\title{
MODA, CULTURA DE CONSUMO E MODERNIDADE NO SÉCULO XIX ${ }^{1}$
}

\section{Fashion, consumption culture and modern times on the nineteenth century}

\author{
Prof $^{\text {a }}$. Dr ${ }^{\mathrm{a}}$. Valéria Brandini ${ }^{2}$
}

\section{Resumo}

Este artigo apresenta uma reflexão teórica acerca da relação entre a moda e a cultura urbana na modernidade industrial do século XIX, onde a primeira é tomada como objeto de representação, mais propriamente, comunicação das novas estruturas socioculturais emergentes da segunda. A moda como discurso, corpus comunicacional em evidência neste período sócio-histórico, é aqui analisada sob uma perspectiva interdisciplinar.

Palavra-chave: modernidade, moda, comunicação, cultura, urbe.

\begin{abstract}
This article presents a theoretical reflection about fashion and urban culture in the industrial modernity period of the XIX century, where the first is taken as an object of representation, or properly, communication of the new social and cultural structures that emerged in the second. Fashion as speech, communicational corpus in evidence in this socio-historical period is analyzed here under interdisciplinary perspective.
\end{abstract}

Key-words: modernity, fashion, communication, culture, urbe.

\section{Resumen}

Este artículo presenta una reflexión teórica referente a la relación entre la moda y la cultura urbana en la modernidad industrial del siglo XIX, donde el primer se toma como objeto de

\footnotetext{
${ }^{1}$ Artigo baseado em pesquisa realizada para tese de doutorado na ECA - USP, em convênio com a Central Saint Martin's School of Fashion (Londres) e Universitá La Sapienza (Roma) com auxílio de bolsa de Doutorado Sanduíche da FAPESP

${ }^{2}$ Possui graduação em Ciências Sociais, modalidade Antropologia pela Universidade Estadual de Campinas (1995), mestrado em Ciências da Comunicação com ênfase em Publicidade e Marketing pela Universidade de São Paulo (1998), doutorado em Ciências da Comunicação pela Universidade de São Paulo em convênio com a Central Saint Martin's School of Fashion and Design e a Universitá La Sapienza (com bolsa de doutorado da FAPESP) (2003). Atualmente é professor conferencista da Universidade Estadual de Campinas, docente horista, professor conferencista da Universidade Estadual de Londrina, professor horista do SENAC Moda SÃO PAULO, professor horista da Universidade Anhembi Morumbi, pesquisador colaborador sênior da Universidade Estadual de Campinas. Avaliadora de cursos e avaliadora institucional do MEC. Pesquisador co-associado do Obervatório de Sinais, especialista em etnografia do consumo e antropologia empresarial. Coordenadora de pesquisas do Grupo Culturas Empresariais da Unicamp. Tem experiência na área de Comunicação, com ênfase em Publicidade e Marketing, atuando principalmente nos seguintes temas: comunicação, antropologia empresarial, moda, consultoria de marcas, grupos de estilo, industria fonográfica e cultura juvenil. Dra Valéria Brandini, PhD. Em Ciências da Comunicação pela ECA - USP. E-mail: brandie@ig.com.br
} 
Moda, cultura de consumo e modernidade no século XIX

de Valéria Brandini

la representación, más correctamente, comunicación de las nuevas estructuras socioculturales de las segundas. La moda como discurso, corpus comunicacional en evidencia en este período socio-historico aquí se analiza bajo una perspectiva interdisciplinar.

Palabras-clave: modernidad, moda, comunicación, cultura, urbe.

\section{MODA: FABRICAÇÃO SOCIOCULTURAL DO CORPO NA MODERNIDADE}

Para se conhecer as características do fenômeno moda na pós-modernidade, das relações entre a moda e a cultura urbana contemporânea faz-se necessária a compreensão do momento sócio-histórico que antecedeu essa era e que consolidou a essência mutante, fluida e efêmera da expressão de moda: a modernidade e a emergência da vida urbana no capitalismo industrial.

Embora o vestuário, como expressão de moda, seja um fenômeno iniciado no século XII, na sociedade ocidental, e a complexidade da história da moda possa, por si só, servir como ilustração da história social do Ocidente, como vemos nas obras de historiadores como Christopher Breward e Anne Hollander, e de pintores como Watteau e Van Gogh, este trabalho tem como foco o bloco histórico situado a partir da modernidade no século XIX, cujas implicações e desenvolvimento têm repercussão direta sobre a moda na pósmodernidade, a condição contemporânea.

Os estudos sobre antropologia urbana da Escola de Chicago nos anos 1940 ampliaram os horizontes da antropologia e de outras ciências para a compreensão de fenômenos e condições socioculturais comuns a grupos e povos que, embora expressassem diferenças geográficas, econômicas e históricas, encontravam-se sob a influência dos mesmos agentes e desenvolviam problemas, soluções, conflitos e alianças semelhantes - as metrópoles afetadas pela modernidade emergente no século

XIX. Novas estruturas sociais e familiares nasciam com a reformulação dos grandes centros urbanos do Ocidente. Imigrações e êxodos, formação de guetos, comunidades, culturas novas que se desenvolviam com a mesma velocidade das novas máquinas geravam um novo mosaico étnico, cultural, econômico nas cidades européias, que influenciavam também o novo mundo. A esse conjunto fenomenológico que revolucionou a vivência humana a partir do século XIX, estudiosos do tema geraram e dedicaram uma nova área de pesquisa a partir da segunda guerra mundial - a Antropologia Urbana. Sob a influência da moderna urbe ocidental, muitos eventos se desenvolveram ao longo do século $\mathrm{XX}$, entre eles a expressão de moda moderna e mais adiante a moda sob o signo da pós-modernidade. 
Dos desdobramentos sobre os estudos da urbe no século XIX, cientistas hoje pesquisam a metrópole do século XXI, entre eles, Massimo Canevacci, Mike Featherstone e Celeste Olalquiaga. Eles dedicam suas pesquisas aos estudos das relações fluidas e instâncias de poder descentralizadas da vivência urbana in progress, realidade que se torna signo nas fantasias e leituras das criações da moda na pósmodernidade.

Portanto, o estudo da expressão de moda, influenciada, afetada e transfigurada pela metrópole - rua - neste início de século XXI e por todas as manifestações culturais, artísticas, comportamentais, econômicas e étnicas que a caracterizam, tem por base investigações antropológicas referenciadas pela urbe nesta pesquisa. Inicialmente, relações entre moda/cultura/urbe, a partir do século XIX, serão abordadas neste capítulo, com ênfase em aspectos antropológicos do desenvolvimento da vida metropolitana e da moda como representação destes.

\section{O SÉCULO XIX}

Vemos que o século XIX apresentou uma revolução nas estruturas da vida social e no âmbito privado no Ocidente graças ao desenvolvimento industrial, à ascensão do capitalismo e à redefinição de valores e códigos morais da vida urbana, elementos formadores da condição que concebemos como 'modernidade'.

A noção de progresso constituiu a base das transformações materiais e sociais ocorridas na época. O poder da tradição sucumbiu em face do poder descentralizado da inovação e a sedução do novo estilizou a vida urbana e as relações humanas, gerando novos padrões de feminilidade e de apresentação da imagem pública.

Mudanças nas relações sociais e de gênero estão 'estampadas' na expressão de moda em emergência no século XIX. A extravagância no traje tornou-se seara feminina e o mundo masculino passou a explorar outras formas de representação do status: se até o século XVIII a espetacularidade no traje masculino constituía uma forma aristocrática de representação de poder, novas convenções sociais, entre elas, a banalização do luxo ostentatório entre a aristocracia, a projeção do corpo humano como extensão do trabalho e a condenação do homossexualismo em países como a Inglaterra, a partir do século XVIII, reduziram a espetacularização no traje do homem, tornando-o escuro e sóbrio.

Não que a exposição dos excessos tenha deixado de representar posse e diferenciação, mas o poder monetário e social masculino passou a estar representado na ostentação das vestes de esposas, mães e filhas. Adventos que veremos a seguir. 
A modernidade emergente no século XIX, imersa na era industrial, trouxe novos aspectos para a vida coletiva nos grandes centros urbanos, gerando transformações na vida econômica, no trabalho, nas relações sociais e na vivência privada das pessoas nas cidades, no nascimento da moderna urbe que antecedeu a vida metropolitana atual. (Villaça \& Góes 1998)

A dissociação entre os domínios público e privado, ocorrida com a ascensão do capitalismo industrial do século XIX, modificou o cotidiano e, conseqüentemente, a figura do indivíduo, que passou a ser constituída com influência do desenvolvimento tecnológico e da industrialização. A partir daí, a figura do homem modelo, do gentleman, aristocrata, refinado, elegante e soberbo dos séculos anteriores foi substituída pela figura austera do empreendedor, como vemos nos trajes masculinos adotados no século XIX.

Sob a visão de Richard Sennett (1982), o capitalismo industrial pressionava a cultura pública urbana à privatização, ao mesmo tempo em que 'mistificava' a vida material em público, especialmente em termos de roupas, em face da produção e distribuição em massa. Novas tecnologias de produção acompanhavam a tendência da "despersonalização" do indivíduo através da uniformização de sua imagem pública, principalmente, no traje masculino.

A industrialização gerou tendências à massificação de padrões. O trabalhador se 'uniformizou' para o novo universo do trabalho e a produção em série eliminou antigas marcas distintivas. Conforme essa padronização aumentava, tornava-se reflexo do proletariado, gerando, entre as classes mais abastadas, uma paixão pela unicidade, pela exaltação de atributos de personalidade, que se concretizou através do consumo e que se tornou evidente através da 'moda do absurdo' e da confusão estilística que imperou nas últimas décadas do século XIX.

A revolução industrial e suas conseqüências sobre a urbe podem ser 'lidas' através das manifestações do vestuário como expressão de moda no século XIX. Mudanças estruturais do comportamento e vivência social urbana que vinham ocorrendo desde o século XVIII foram potencializadas com o capitalismo industrial do século posterior. Alterações dos códigos morais de conduta masculina e feminina se fizeram nas reviravoltas da expressão de moda na Era Moderna.

Até o século XVIII, na Europa, a aceitação do comportamento aristocrático licencioso - em que os homens de classes hierarquicamente superiores relacionavam-se sexualmente com parceiros masculinos e femininos (especialmente na Inglaterra) - 
organizava o universo masculino em torno do esplendor da imagem do homem - sua importância era maior quanto maior fosse a ostentação em seu traje. A linguagem corporal afeminada e os maneirismos afetados eram sinal de poder aristocrático, a serem imitados por homens burgueses que, em busca de promoção social, infringiam leis suntuárias e adotavam elementos do estilo de vestimenta dos aristocratas, além de hábitos e preferências sexuais dos mesmos.

Em busca de ascensão, a burguesia não só transgredia leis suntuárias como também institucionalizava um emergente hedonismo através do consumo de prazeres e principalmente de moda.

Segundo o historiador de moda Christopher Breward, da Central Saint Martin's School of Fashion, a partir do fim do século XVIII, a aristocracia passou por uma reconstrução de sua imagem pública, abolindo a ostentação como exibição de poder, adotando vestimentas mais simples. A idéia de ostentação assumiu uma conotação negativa, principalmente na Inglaterra, sob o reinado do Rei George e da Rainha Charlotte, que condenavam os excessos de Robespierre e Napoleão. A aristocracia respondeu então renunciando à exuberância na moda.

Essa reestruturação da imagem pública e do comportamento, que data da segunda metade do século XVIII, representa uma reformulação de símbolos de poder social, também muito influenciada pelo não-conformismo religioso e pela ênfase na relação entre traje simples e retitude moral.

$\mathrm{Na}$ Inglaterra, o peso da religião, principalmente dos Quakers, a condenação do homossexualismo e do bissexualismo, a exemplo do fechamento das 'Molly Houses' londrinas - bordéis de homossexuais onde homens da elite refugiavam-se do casamento e se relacionavam com parceiros do mesmo sexo -, além da reformulação dos conceitos sobre a confecção da imagem pública, tornaram a vida urbana, a partir da segunda metade do século XVIII, um território um tanto ‘ameaçador' por conta das múltiplas condenações visuais e comportamentais que se infringia ao indivíduo.

Segundo Sennett, a vida pública converteu-se (em oposição aos ideais do Iluminismo, em que representava um conjunto de relações sociais) em uma instância moralmente inferior. Entre o proletariado, o capitalismo industrial passou a ditar a vida material do domínio público, a produção em massa de roupas e o uso desses padrões de produção em massa para alfaiates e costureiras significavam que a vida pública urbana começava a adotar uma aparência semelhante, e que as marcas públicas estavam perdendo suas formas distintivas. Com a dimensão adquirida pela máquina, entre a emergente classe operária, o corpo se "uniformizava" para o trabalho e as diferenças sociais que se 
expressavam pela composição indumentária - diferenças importantes, como ressalta Sennett, para se saber da própria sobrevivência, num meio de estranhos e em rápida expansão - tornavam-se ocultas.

O homem público sofreu uma tendência a se tornar indiferenciado no início do capitalismo industrial, através da confluência da produção em massa e da homogeneização da aparência. Inicia-se então, através do consumo, o ato de se "revestir" coisas materiais com atributos ou associações próprias à personalidade íntima, o que Marx categorizava como o 'fetichismo da mercadoria' e o que, posteriormente, Baudrillard denominaria 'sistema dos objetos'.

Temos a emergência do que Baudrillard caracteriza como sendo a substituição da relação humana, viva e conflituosa, por uma relação personalizada nos objetos.

Segundo o autor, no estágio de produção artesanal, os objetos refletem as necessidades na sua contingência, na sua singularidade, então o sistema de produção se adapta ao sistema das necessidades. Na era industrial, os objetos fabricados adquirem uma coerência que vem da ordem técnica e das estruturas econômicas. O sistema das necessidades torna-se menos coerente que o sistema dos objetos e este impõe coerência e adquire poder de modelar uma civilização. (Baudrillard 1997: 197)

A era industrial e o avanço do capitalismo no século XIX trouxeram a idéia de dissociação entre o homem que trabalha e o seu trabalho, pois já não o controla, mas precisa vendê-lo. Tal ocorrência, que Marx classificou como a alienação provocada pelo capitalismo, reflete a idéia de transformação do homem em máquina de produção. Nesse processo, o indivíduo se desumaniza e o seu produto (os bens produzidos pelo trabalho físico) adquire características humanas, psicológicas, e induzem o homem à sua compra como forma de se re-humanizar através de bens adquiridos. Surgem, então, novos padrões de consumo e a moda torna-se ícone dos mesmos.

Essa homogeneização do homem público predispôs a impessoalidade. Assim, a vida pública converteu-se numa agregação de estranhos. Tem início, então, a busca por diferenciação através do conteúdo "humanizado" existente nos produtos que "personalizam" o indivíduo através da forma de sua composição indumentária: os novos códigos de moda.

Para Sennet, o isolamento e impessoalidade em meio ao espaço público e a ênfase emergente nas transações psicológicas se complementam. A proteção da vigilância de outrem por meio do isolamento, em relação à esfera pública, é compensada com a exposição supervalorizada para aqueles com quem se deseja fazer contato em eventos sociais variados. 
Podemos pensar que essa exposição é caracterizada por máscaras sociais, por meio das quais as pessoas se representam na rua (esfera pública) e muito do que são estas máscaras sociais constituíra-se pela composição indumentária - a moda em ascensão. As aparições em público, com seu caráter mistificador, tinham de ser levadas a sério, pois poderiam gerar indícios da pessoa oculta por trás da máscara, ou do "eu” por debaixo da roupa.

Temos, como exemplo desta dicotomia entre público e privado, a composição indumentária usada na vida pública na era vitoriana, em que o corpo é recoberto, escondido, apertado em roupas escuras que buscam negar e reprimir a sexualidade, em contraposição às roupas de dormir usadas na mesma época na vida privada, caracterizadas por amplas camisolas claras, confortáveis e que permitem a liberdade do corpo.

Sennett salienta que essas mudanças, sinais gritantes de uma vida pessoal desmedida e de uma vida pública esvaziada, ficaram por muito tempo incubadas, e são resultantes de uma mudança que começou com a queda do Antigo Regime e com a formação de uma nova cultura urbana, secular e capitalista. $\mathrm{O}$ autor resssalta:

O secularismo que surge no século XIX era de um tipo completamente oposto ao do século XVIII. Baseava-se em um código do imanente, de preferência ao transcendente. Sensações imediatas, fatos imediatos, sentimentos imediatos já não tinham que se encaixar em um esquema preexistente para serem entendidos. $O$ imanente, o instante, o fato eram realidade por si mesmos. Os fatos são mais fiáveis que o sistema - ou, melhor dizendo tornou-se um sistema... Qualquer aspecto visível desta pessoa era de algum modo verdadeiro, porque tangível; de fato, se essa aparência era um mistério, era uma razão a mais para ser levada a sério. Quando uma sociedade se dedica ao princípio de que as coisas têm significações nelas próprias, faz desse modo penetrar um profundo elemento de dúvida sobre si mesma no seu aparato cognitivo, pois qualquer exercício de discriminação poderá ser um equívoco. Fantasiar que objetos físicos tinham dimensões psicológicas tornou-se lógico dentro dessa ordem secular. (Sennett 1982: 37)

Quando emergem as questões e as preocupações em torno do "eu" em exposição, a psicologia ganha terreno e a vida pública torna-se um espaço onde se tenta desvendar o eu oculto dos anônimos em meio à multidão através de "pistas", traços, ou até de pequenos deslizes que possam revelar a personalidade do indivíduo. Como pequenos detalhes de suas roupas, ou a utilização destes ou daqueles signos de moda.

Se, na era anterior à revolução industrial, as formas de exposição na vida pública revelavam a posição social ocupada pelo indivíduo, com a roupa sendo um referencial do status social ocupado por uma pessoa, (já que roupa e estilo se ancoravam na lógica da tradição), a partir do século XIX, com a emergência dos estudos psicológicos, em meio às posturas repressivas da era vitoriana, as pessoas passam a acreditar que suas roupas, seus gestos, seus gostos revelam não mais sua origem social, mas sua personalidade. O individual se sobrepõe ao coletivo, assim como a vida privada torna-se mais segura que a 
vida pública.

A secularização atribuiu todo um novo estatuto simbólico ao indivíduo, uma mistificação das características humanas, que se acredita estarem presentes nos objetos, nas roupas, nos usos e costumes do sujeito. Ela fez com que a imagem, a composição indumentária e os pequenos detalhes da roupa ou dos produtos consumidos caracterizassem uma exposição involuntária das emoções, revelando o "eu" que não se expõe abertamente na vida pública.

Essa mistificação em torno da imagem como reveladora da personalidade, criou um novo estatuto para a moda, a crença na subjetividade revelada na imagem, na roupa. Com a emergência da problemática do "eu" no século XIX, (a exemplo das descobertas de Freud), em decorrência da divisão da vida urbana em esfera pública/ esfera privada, o estatuto da moda assume novas dimensões, tornando-se instrumento da busca narcisista por autosatisfação, personalização e individualização crescente. O indivíduo agora é revestido pela imagem pública, essa imagem construída a partir da moda, que se torna referência do sexo, do prazer, da auto-afirmação e que se confunde com o que significa

o indivíduo em si, gerando uma despersonalização dos conteúdos internos deste e a concepção de que as "pessoas são o que vestem”, em esfera pública, "as pessoas são sua imagem".

Podemos dizer que o século XIX foi um momento de ruptura, transformação e adoção de novos valores e referências derivadas do que chamamos de modernidade. O novo se sobrepõe à tradição, o individual ao coletivo, o privado ao público e adventos, como o consumo e a técnica derivados do capitalismo industrial, tornam-se símbolos a representar uma nova era.

Até o século XIX a sociedade não se orientava pela noção de progresso. A partir da modernidade, a técnica seduz e influencia instâncias da vida social e cultural através da descoberta da eletricidade, do trem, da fotografia. A arte se volta para a discussão do presente e a industrialização, o avanço técnico e o debate sobre o indivíduo influenciam os artistas da época e os couturiers que emergem na segunda metade do século.

Segundo Breward (1995), as inovações tecnológicas, a reorganização do comércio e a industrialização, ocorridas na modernidade, geraram mudanças profundas na concepção e expressão de moda na segunda metade do século XIX. A idéia de modernidade simbolizando o futuro, o progresso, o novo - motivou a disseminação do gosto pela moda, códigos sociais baseados na hierarquia do poder tradicional cederam lugar ao interesse de consumo da expressão de moda.

Breward analisa, a despeito do psicologismo enfatizado por Sennet, outras razões 
que converteram o espaço privado em seara protetora e o espaço público ameaçador na vida na urbe. Nos anos 1830, ocorre um revival do protestantismo não-conformista na Europa, principalmente na Inglaterra, o que tornou a idéia de feminilidade associada à casa. Nascese na casa, vive-se na casa, morre-se na casa, o que torna a vida doméstica mais valorizada que as ocorrências da esfera pública. Jornalistas da época associam a este advento o aumento das formas góticas em moda nos anos 1840. Contudo, Breward acredita que a mudança de práticas de negócios e o crescimento de uma segregação suburbana física entre casa e trabalho foram também grande influência para esta adoção da vestimenta gótica, simples e austera.

A partir dos anos 1830, a mulher passa a ser responsável pela imagem pública de sua família. Esposas tornam-se responsáveis, no lugar de seus maridos, pelas formas expostas em público que expressavam e determinavam o status social. Com isso, questões da sexualidade masculina e feminina, são reestruturadas e influenciam novas regras para a vida pública e privada de homens e mulheres.

No século anterior, precisamente de 1780 a 1820, a vestimenta feminina era baseada no estilo neoclássico, com a cintura alta - logo abaixo dos seios - e saias folgadas que, a partir da cintura, desciam até os tornozelos sem definir a silhueta feminina. Em contraposição a certa 'simplicidade' e classicismo do traje feminino, a vestimenta masculina atingia o extremo de adornamento, colorido e requinte.

Percebe-se que, até a modernidade, modelos de feição do traje, ainda doutrinado pelas eras de tradição, mantinham-se em voga durante décadas, ao contrário das eras de inovação e efemeridade que caracterizam a moda contemporânea, iniciada na modernidade emergente no século XIX.

Segundo Lipovetsky, a moda foi um agente de transformação a partir do fim da idade média. Ela permitiu que a vaidade humana, o narcisismo e o desejo estético projetassem o homem a subverter a ordem imutável da tradição. Para acompanharmos a idéia traçada por Lipovetsky, associando moda a democracia e liberdade, é necessária a compreensão de que, até antes do século XIV, o traje servia ao domínio da tradição, ao culto de antepassados e não ao valor estético, à sedução. A busca pelo prazer estético e sexual era exterior à composição indumentária, esta, 'embalagem' a diferenciar hierarquias sociais. Foi a partir dos séculos XVII e XVIII que a moda consolidou-se como prazer estético, elemento de individualização das aparências, de diferenciação como elemento de ambição e tentativa de mobilidade social, em contraposição à desigualdade imutável infringida aos homens nas eras de tradição.

Se, a partir do século XVII, a moda como hedonismo, individualização, prazer 
frívolo, representação do amor cortês - heterossexual e homossexual -, veículo de exposição da vaidade masculina, projetava o poder masculino através da exuberância, a partir do século XIX, a situação se inverte e novos códigos de poder são representados por uma inovação das significações nas vestimentas masculinas e femininas.

Historiadores da época associam a busca pelos prazeres da construção da imagem pública através da moda a uma forma de escapismo, semelhante à consagração das novelas e do amor romântico, uma busca por prazeres individuais que Lipovetsky considera como sendo o corolário da nova relação de si com os outros, do desejo de afirmar uma personalidade própria que se estruturou ao longo da segunda idade média nas classes superiores. Individualismo, representação da subjetividade, exaltação da unicidade dos seres e seu complemento: a promoção social dos signos e da diferença pessoal. (Lipovetsky 1989)

Conforme a mulher assume a função de representante do status social de sua família, a casa e as atividades da vida privada aumentam em importância social. Ocorre neste momento, uma feminização da cultura estética do século XIX, potencializada pela emergência da mídia impressa feminina (as revistas femininas) e a produção e consumo de bens voltados ao universo feminino. Concomitantemente, a moda masculina, em oposição aos séculos anteriores é renegada a vestimentas bem menos ornamentadas. Vemos, neste momento, a ocorrência da consagração da vida pública acima descrita por Sennet.

Entretanto, a partir dos anos 1850-60, o desenvolvimento tecnológico e industrial afetou drasticamente relações e representações da vida pública e privada. Ao mesmo tempo em que as condenações de exibição da vida material impostas pela religião e o modelo da mãe e esposa modesta e recatada, desapegada das coisas materiais, eram consensualmente aceitos como códigos morais, novas doutrinas irresistíveis da vida moderna, industrial e capitalista tomavam corpo na vivência urbana.

A partir do ano de 1855, a tecnologia emergente, gerando inovações na produção e uma reestruturação dos padrões de feminilidade, adicionou elementos extravagantes ao vestuário feminino. Ocorre a partir daí o que Breward caracteriza como espetacularidade na vestimenta feminina com expressão de moda. Até os anos 1860, qualquer mulher vestindo moda, andando pelas ruas desacompanhada, era segregada como prostituta, mas, a partir de então, o uso de modas tornou-se indissociável da vida urbana.

Em 1856 ocorre o que acreditamos ser um dos principais efeitos da modernidade (leia-se: industrialização, capitalismo agressivo, inovação tecnológica) na moda, reestruturando relações entre imagem pública e vivência urbana: as crinolinas de metal passaram a ser usadas, o que enfatizou o uso do artifício, o gosto pelo moderno e pelo 
frívolo e o que moralistas da época acusaram de ser o início da imoralidade da vestimenta moderna. Os anos 1860 se estabeleceram como a década-marco da crinolina de metal.

Conforme a moda moderna produz e é produzida por inovações tecnológicas e industriais, comércio e indústria voltam-se para o emergente 'negócio da moda', o que gerou, em países como Inglaterra e França, a emergência de um enorme número de patentes registradas de produção de crinolinas, sob os distintos nomes de: Ladies Spring Dress Improver, ou The Ladies Petticoat or Dress Dilator, e até Spiral Spring Petticoat Cord. Ao lado da 'revolução da crinolina', as novas cores de tinturas para tecidos descobertas na época impulsionaram a indústria química, que passou a desenvolver novos métodos que reduzissem os custos da coloração de tecidos.

Percebemos que, já no século XIX, a expressão de moda é subsidiada pela produção de pequenas indústrias adjacentes que geram uma reformulação industrial e de mercado. Empresas de extração de metal, empresas de produção de tintas para tecidos, fábricas de crinolinas, uma nova indústria de produção de mídia impressa especializada em revistas femininas, entre outras, geram um complexo de pequenas indústrias específicas, especializadas na produção de materiais para a confecção de vestes com expressão de moda.

A cintura e as mangas dos vestidos femininos estreitavam, ao passo que as saias aumentavam ao máximo em diâmetro. A jovem consumidora de moda tornava-se diametralmente oposta ao modelo de mulher modesta, quieta e resignada dos anos 1840. Ela se tornou vaidosa, exibicionista e exaltada. O consumo de moda contribuiu para a formação da imagem pública da 'nova' mulher do século XIX, ao abolir o uso do traje gótico do início do século e adotar uma atitude de consumo vigorosa, ávida pela novidade. Extravagante, a mulher expressava mais liberdade e independência.

Até 1861, crinolinas ainda eram feitas manualmente. A partir de 1862, a produção de crinolina de metal já era responsável por mais de um sétimo de extração de ferro na mina de Sheffield, na Inglaterra. Um marco da relação entre moda e modernidade industrial ocorreu neste ano: a mina de ferro de Bedson foi aberta para a extração de metal destinado estritamente para a produção de crinolina. Uma nova indústria, a da produção de crinolinas se consolidou na sociedade inglesa. Isso simbolizou a união entre aplicação de novas tecnologias e organização sistemática do processo industrial na reforma da natureza e do caráter da veste com expressão de moda e o design no século XIX.

Em 1856, o químico William Pekin inventou a anilina de coloração púrpura, o que serviu ao aumento das extravagâncias na então emergente indústria da moda. Com os efeitos das novas cores e a adoção da crinolina pelas mulheres da época, o exibicionismo 
tornou-se a decorrência da relação modernidade/moda. Mudanças na presença física, no status e na projeção da feminilidade ocorreram a partir da segunda metade do século XIX, o que alterou o aspecto das vias públicas - a espetacularidade da vestimenta feminina se tornou "vitrine" das transformações tecnológicas e industriais em emergência. Essa 'luminescência' da vestimenta feminina era também o reflexo do espírito empreendedor do século XIX.

O aparecimento das lojas de departamentos e das revistas femininas de costura alterou a rotina das mulheres, agora mais atuantes na esfera da vida pública. Se nos anos 1830 as mulheres comunicavam publicamente o status social e moral de suas famílias, adotando trajes de resignação em aparições públicas, a partir de 1850-60 elas foram disciplinadas pelo capitalismo agressivo do mundo masculino, tornando-se representações vivas da condição social de seus homens e daquilo que estes ofereciam a suas famílias. $\mathrm{O}$ exibicionismo público nos trajes da mulher tornou-se o medidor de forças do poder econômico e influência social masculinos.

Neste momento, concordamos com Baudrillard, em oposição a Lipovetsky, em sua, um tanto misógina, porém instigante, discussão sobre a transformação da mulher em objeto de representação do status de seu homem. Se, em algum momento da história, esse fato se tornou realidade, foi certamente na segunda metade do século XIX, perdendo força, posteriormente, no início do século XX, com a maior inserção das mulheres no mercado de trabalho.

Para Breward, as razões para a espetacularidade da moda no século XIX - para além de leituras reduzidas sobre a sexualidade na Era Vitoriana - com a adoção da crinolina e dos chapéus extraordinários, têm explicações em áreas como a cultura impressa (e as revistas femininas), a expansão industrial, a ideologia doméstica e a reorganização das atividades de compra da nova moda.

Em 1864, ano em que as saias assumiram o máximo de circunferência, já podemos notar a sucessão de 'diferenciações marginais'de que nos fala Lipovetsky, nas vestes femininas da época, como pequenas variações ocorridas em um mesmo traje sucessivamente, a fim de incorporar inovações e detalhes muitas vezes ditados por revistas femininas da época.

Essas mudanças e adições em vestidos ocorriam graças ao uso da máquina de costura doméstica, primeiro produzida nos anos 1850, patenteada pela Singer em 1851, e adotada para a realização de pequenas alterações em casa. $\mathrm{O}$ máximo de circunferência adotado para as saias servia bem ao propósito de exposição de novos enfeites, adereços ou cores cuja produção aumentava vertiginosamente graças ao desenvolvimento tecnológico e 
industrial.

Nos anos 1860-70, saias enviesadas com painéis pintados, no estilo na época chamado "princess line" ou forma "S", eram enaltecidas pela tecnologia. E suscitaram novos modos de produção e consumo.

Características do design de moda que são presentes e influenciam a moda até os dias de hoje tiveram início nos anos 1860, quando costureiros parisienses começaram a estudar costumes históricos do período Luís XV e XVI para a criação e confecção de vestidos com expressão de moda. Muitos pensam mais em copiar do que criar novos estilos, todavia o estudo de momentos históricos, culturas antigas e sociedades arcaicas torna-se uma constante na feição dos trajes femininos da época, como a adoção de motivos gregos na confecção de vestidos em estilo 'princess line' e a imitação de estilos dos séculos XVI e XVII.

Também a questão da diversidade de estilos de moda já se faz presente no século XIX. Ao mesmo tempo em que indústria e tecnologia projetaram o uso de saias de enorme circunferência, com painéis extravagantes pintados e cores gritantes, misturando tecidos e ornamentos diferentes, a emergência da alfaiataria nos vestidos femininos, com uma forma mais severa, cores sóbrias e tecidos de uma só padronagem - advento também fruto da modernidade pela adoção da máquina de costura caseira - competia com a extravagância do estilo 'princess line'.

Um outro elemento influenciava a estética da moda na época: os uniformes. Segundo a pesquisadora Elizabeth Wilson, a roupa para praticar esportes e diferenciar trabalhadores e autoridades marcou a consolidação de padrões de indumentária no século XIX. Wilson salienta que os uniformes foram o primeiro tipo de vestuário produzido em massa. No século XIX eles tiveram um significado novo, faziam parte de uma crescente classificação, marcação e estandartização da vida na idade das máquinas e eram manifestação da tentativa burocrática de fixar o anonimato da metrópole, simbolizando o avanço do Estado Moderno na vida do indivíduo.

Nos Estados Unidos, os homens adotaram, a partir do século XIX o uniforme de montaria e a roupa de trabalho para andar pela cidade, o que tornou o uniforme esportivo e de trabalho, o padrão de indumentária adotado como roupa urbana. Na Inglaterra e França, a forma ' $S$ ' cedeu gradualmente lugar à versão feminina do terno de montaria, com saia mais justa e casaco. Wilson ressalta que o uniforme é contraditório, pois diante da finalidade de submergir a personalidade e apagar a individualidade pode por vezes reforçála.

Esse período constituído pelas últimas décadas do século XIX, um período de 
confusão estilística - quando as imensas saias sustentadas pela crinolina de metal desfilavam pela urbe ao lado de 'tailleurs' que imitavam os sóbrios ternos masculinos - é a representação viva da moda como 'vitrine' das transformações socioculturais de uma época.

A emergente indústria da moda passou a incorporar todas as inovações tecnológicas e industrias que ocorriam na época. As gigantescas saias decoradas com painéis pintados com motivos gregos, representações históricas dos séculos XVI e XVII, entre outros motivos, foram a consagração da nova produção industrial da crinolina de metal. Ao passo que os trajes femininos mais sóbrios, que exaltavam a alfaiataria, foram a consagração da máquina de costura e da possibilidade da produção de alfaiataria em escala semi-industrial; além de representarem a adoção de vestimenta mais conveniente para as mulheres sujeitas ao trabalho, que deslocavam-se com freqüência e precisavam de adaptação da roupa à atividade de trabalho.

Ambos os estilos foram condenados como 'ausência de gosto', mas o que importa, se a sedução da novidade, busca de diferenciação e incorporação da noção de moderno é o que vale no emergente sistema de moda do século XIX?

\section{MODA MODERNA: CÓDIGO URBANO}

Foi a partir da segunda metade do século XIX que a roupa com expressão de moda tornou-se um fenômeno, um sistema de produção, difusão e consumo inovador e que se manteve por um século. A Alta Costura surge então como uma conjugação entre as belas artes, o rigor técnico e um processo de personalização, da escolha individual, da sedução que torna o corpo objeto de desejo, de paixões, de prazer estético. (Vincent-Ricard 1986)

Ao mesmo tempo em que a Alta Costura se instaura sob o signo de uma diferenciação marcada em matéria de técnicas, de preços, de renomes, de objetivos, de acordo com uma sociedade, ela própria dividida em classes, com modos de vida e aspirações nitidamente contrastados (Lipovetsky, 1989), a confecção industrial se opõe a ela, com uma produção de massa, em série e barata, imitando de perto ou de longe os modelos prestigiosos e griffes de Alta Costura. Segundo Lipovetsky, a confecção industrial precedeu o aparecimento da Alta Costura:

Desde os anos 1820, instala-se na França, à imitação da Inglaterra, uma produção de roupas novas, em grande série e baratas, que conhece um verdadeiro impulso depois de 1840, antes mesmo da entrada na era da mecanização com a introdução da máquina de costura por volta de 1860. (Lipovetsky 1989:71) 
As roupas produzidas em série por fábricas, em países como Inglaterra, França e Estados Unidos, já no início do século XX, eram bastante rudes, mal-acabadas, compradas apenas pela grande massa de operários muito pobres, enquanto as classes trabalhadoras que dispunham de mais recursos mandavam confeccionar suas roupas em costureiras que produziam modelos sob medida. A veste usada sobre o corpo definia diferenciação de classes, ao ponto que, inicialmente, a homogeneização da composição indumentária era sinal de pobreza.

Traçando um paralelo entre o surgimento da Alta Costura e o contexto sociocultural em que se encontrava o Ocidente na segunda metade do século XIX, a evolução das cidades em meio à era moderna alterou os estatutos de vida coletiva e de vida íntima. A intimidade tornou-se refúgio, local da exposição das subjetividades e descoberta e valorização do "eu". A rua, enquanto território da vida coletiva, torna-se um verdadeiro palco, onde as subjetividades são protegidas em função de "personas", máscaras sociais que valorizam detalhes da personalidade que, exposta em público, pode revelar indícios das subjetividades omitidas.

Toda forma de utilização de objetos que, acrescidos de traços de humanização tornassem a imagem pública caracterizada por elementos de uma suposta personalidade, se constituíram em formas de comunicação de valores possuídos por um indivíduo. A vida pública é, pois, o palco da Alta Costura no século XIX.

Conforme Sennett, a "impersonalidade" constitui-se neste período como um mal moral. Artistas que atuam em público assumem o status de personalidades públicas. As pessoas desenvolveram mecanismos de defesa contra sua própria crença no desvendamento involuntário da personalidade através do que expressavam em sua imagem e palavras e contra a superposição do imaginário privado e público. Curiosamente, essas defesas levaram as pessoas a elevarem os artistas que atuavam em público ao status peculiar, glamouroso e fantasioso de pessoas públicas que ocupam hoje em dia. Segundo Sennett:

O ator e o músico ascenderam na escala social muito acima do nível da criadagem onde se encontravam no Antigo Regime. A ascensão social do artista era baseada na ostentação de uma personalidade vigorosa, excitante, moralmente suspeita, inteiramente oposta ao estilo de vida burguesa normal, na qual se evitava, através da supressão dos seus sentimentos, ser lido como pessoa. (Sennett 1982: 43)

No momento em que a imagem pública se torna um sistema de representação pessoal (por vezes, verdadeira "dramatização"), a categoria "personalidade" ascende a um nível de legitimação do indivíduo frente o social. Ao contrário da "fabricação do corpo" realizada pelos povos primitivos, tem-se a fabricação do indivíduo por meio dos signos 
estéticos, verdadeiros símbolos que encobrem o corpo, a comunicar atributos de uma dada personalidade.

Como forma de controlar a exposição de sentimentos, a expressão involuntária do "self", ao mesmo tempo em que se tentava mostrar uma personalidade autêntica (todavia respeitosa,"distinta"), havia um aumento sensível do cuidado com os signos que compunham a indumentária.

A abertura da maison de Charles-Frédéric, na rue de la Paix, em Paris, em1857 que confeccionava trajes cujo apelo da autenticidade, na forma de roupas únicas, confeccionadas sob medida, com modelos inéditos, apresentados em salões luxuosos aos clientes e executados após sua escolha, segundo as medidas da compradora - constituiu um exemplo vivo da "personalização" do indivíduo por meio do consumo simbólico de moda a partir do capitalismo industrial.

A Alta Costura - instituída inicialmente como a "indústria do luxo", da inovação e da fantasia sem precedente, a ser seguida pelas mulheres up to date mundo afora - teve como cânone, a distinção. Gradualmente, ao longo do século XX, a exibição do luxo na Alta Costura tornou-se símbolo de mau gosto e a verdadeira elegância exigiu discrição e ausência de aparato, a exemplo do desuso, já no século XIX, da forma "S" pelas mulheres.

Podemos dizer que o apelo da "distinção" nos trajes de Alta Costura representa, na modernidade, a lógica da diferenciação proposta por Baudrillard (1997) (por meio da qual diferenciamo-nos dos outros ao comprarmos em nome de todo mundo, já que, desejar algo é subentender que todos o desejam e; nenhum desejo, mesmo o sexual, subsiste sem a mediação do imaginário coletivo). Comprar um traje de Alta Costura, que representava distinção, significava comprar um objeto de desejo comum, que se usaria em nome da diferenciação.

Seguindo a lógica de Baudrillard, poderíamos dizer que a sedução proposta pela distinção em Alta Costura, significando personalização e autenticidade representadas pelo consumo da roupa e, ao mesmo tempo, concorrência e conluio, constituiria a funcionalização do consumidor através da fabricação da personalidade por meio da moda.

No caso da Alta Costura, a moda apresentou um dos princípios de divisão entre a classe dirigente e as classes populares (Bourdieu 1975:08), ancorada na tradição em oposição ao "moderno". A moda surge como uma representação e reafirmação de valores que distinguem a classe dominante das demais. Como vemos em Baudrillard, o consumo motivado pela personalização (e estilo) concretiza uma decupagem social e, através dessa decupagem, concretiza a imposição de uma ordem e, através desta ordem, concretiza a imposição de um porvir objetivo - materializado em objetos para diferentes grupos sociais. 
(Baudrillard 1998).

Podemos dizer que a Alta Costura constitui uma das mais fortes instâncias de diferenciação e reafirmação das classes dominantes pelo consumo, pois não apenas sua produção sugere a linguagem da exclusividade, da autenticidade e do refinamento (Bourdieu 1975), valores perpetuados por estas classes, como o acesso a esta produção é restrito a uma minoria, a clientela constante que alavancava o nome das maisons.

Calcada na distinção e na afirmação do "bom gosto", a Alta Costura assumiu, em meados do século XX, lacunas deixadas pela grande arte, cuja apreciação e consumo sempre serviram como diferencial da classe dominante, não apenas pela representação de valores que sugere, mas pelo desenvolvimento de uma linguagem estética que, ancorada nas "belas artes" e no princípio de criação artística de seu costureiro, evidencia atributos de uma nova forma de arte.

Embora a Alta Costura aproxime-se muito do universo das belas artes, a diferença está na relação tempo/espaço ocupados por ambas. Enquanto nas belas artes o valor de uma obra possa demorar a ser descoberto (consolidando-se e intensificando-se com o passar dos anos, décadas, séculos e chegando a se tornar universal), a roupa gerada pela Alta Costura é produzida para ter consagração imediata, a data fixa que orienta a temporalidade das inovações, tornando a roupa e seu estilo obsoletos na passagem de uma coleção à próxima e sempre associando-a, quando antiga, a um padrão, uma coleção, um referencial temporal e espacial efêmero que a torna "démodé".

Todavia, é o aspecto histórico, praticamente antropológico, que associa uma dada estética, padrões de estilo e comportamento codificados no traje a um momento sóciohistórico, que converte o post morten da peça numa atribuição de objeto simbólico.

Portanto, acreditamos que parte da caracterização da moda como uma forma de arte - neste caso, da associação entre Alta Costura e belas artes - deriva da hierarquização interna do campo da moda e da correlação entre esta e o processo de criação/comercialização da Alta Costura, em que a autenticidade e o valor de distinção atribuídos a uma peça visam conceder-lhe uma "aura", no sentido 'Benjaminiano' do termo, ancorada no capital de autoridade estética adquirido pelo bem de moda através da posição hierárquica do costureiro.

A indústria do luxo na Alta Costura também foi a referência para o desenvolvimento de uma indústria diametralmente oposta - a confecção industrial foi uma das primeiras manifestações do consumo de massa, homogêneo, estandartizado, indiferente a fronteiras.

Paulatinamente, no decorrer do início do século XX, avanços no desenvolvimento 
técnico industrial, assim como as mudanças de valores modernos, levaram, segundo Lipovetsky, à atenuação das diferenciações heterogêneas no vestuário das classes, em benefício de toilletes ao gosto do dia para camadas sociais cada vez mais amplas.

A partir desse momento, em decorrência das mudanças nos códigos sociais, no comportamento dos cidadãos em vida pública, ocorridas inicialmente no século XIX, os rituais da exposição pública têm como cânone a discrição, a proteção do 'eu' em meio à multidão de estranhos. O indivíduo passa a se vestir com base na impessoalidade, escondendo as pistas que revelam a personalidade e que poderiam resultar na exposição involuntária das subjetividades através do traje. Ele incorpora o despojamento como aparência distinta, a revelar o isolamento daqueles que querem se distinguir da multidão.

A heterogeneidade dos rituais de exposição pública do século XIX, com toaletes marcadamente dessemelhantes entre classes sociais distintas, a expressar a ordem aristocrática cujo princípio de distinção repousava no fausto ostentatório, na exibição do luxo por parte das classes mais abastadas, cedeu lugar a uma forma de exibição pública mais homogênea ao longo do século XX, que rejeita o princípio de exibição majestosa e superior da hierarquia. Como vemos, a partir dos anos 1920, nas criações de Chanel.

A multidão, segundo Sennett, é o modo pelo qual as paixões dos homens são o mais espontaneamente expressas; a multidão é o homem-animal libertado de suas rédeas. Tal imagem passou a ter um caráter explicito de classe. As pessoas que expressavam seus sentimentos de forma mais explícita eram vistas comumente como Lumpen-Proletariat, as subclasses ou os desajustados sociais.

Chamar a atenção em público, por meio de palavras, gestos ou traje, tornou-se, pois, coisa de classes inferiores, de pessoas sem refinamento, do proletariado sem cultura nem elegância, ou, de certa forma, de artistas, cuja atitude de exposição pública, por si só, já fazia com que lhes fosse atribuído um caráter suspeito, imoral, perigoso, dotado de uma liberdade ('sem rédeas') que ao mesmo tempo fascinava e amedrontava e, independentemente de seu nível financeiro, lhes relegava ao patamar da marginalidade social.

Conforme Lipovetsky, a alteridade social, longe de ser supersignificada no traje, torna-se então oculta em razão da decadência dos signos da suntuosidade ostensiva. O luxo permaneceu sob outros contornos, como signo de bom gosto e refinamento na Alta Costura. Todavia, a simplicidade como forma de distinção não significou uniformização ou igualação do parecer; novos signos de distinção tomaram o lugar do luxo ostentatório, como as griffes, a esbelteza, a juventude, o sex-appeal, a comodidade, a discrição. As diferenças sutis ou, conforme Lipovetsky, 'diferenciações marginais', tornaram-se o 
referencial de alteridade social.

O apelo da composição indumentária a partir do século XX não eliminou os signos da posição social; todavia atenuou-os, promovendo pontos de referência que valorizam sobremaneira os atributos mais pessoais, os quais se encontram menos no traje que no corpo, este, consagrado como o novo parâmetro da moda.

Com a entrada das mulheres no mercado de trabalho e na prática de diversas atividades outrora territórios de domínio exclusivamente masculino - como os esportes -, as práticas desenvolvidas pelo corpo suscitaram uma adequação do traje, ao mesmo tempo em que a imagem da mulher se desunificou, em decorrência dos novos papéis sociais por ela desempenhados a partir do século XIX.

Acompanhando a inserção da mulher em novas atividades, a moda recriou os novos universos por ela adentrados, pela criação de imagens destes novos papéis, na forma de "personagens" definidos pela composição indumentária a eles adequada: a tenista (e o traje esporte), a motorista de automóvel, a aviadora (e os trajes militares), a desbravadora do deserto (e o traje cáqui), a amazona (e as calças com culote), entre tantos outros estilos de indumentária que se tornaram referência para a criação de moda.

A moda, a partir do século XIX, tornou-se uma extensão do ethos social na moderna urbe. Através da sucessão de estilos de roupa gerados ao longo do século, podemos "ler" a realidade social e o universo cultural das gerações que se seguiram no decurso do mesmo. Isso é possível porque a roupa, na categoria de composição indumentária, é composta em sua forma e significado por símbolos que representam a evolução das sociedades. Por meio dela podemos observar as mudanças ocorridas nos papéis sociais, na vida pública e privada dos indivíduos, assim como perceber a importância adquirida pelo corpo e sua ornamentação nas sociedades complexas, sobretudo, a partir do contexto social ao longo do século XX.

\section{O SÉCULO XX E A FEMINIZAÇÃO DA MODA}

“... É uma questão de roupas. Isso é o que me humilha - falando sobre elogios - andar em Regent Street, Bond Street, etc. e ser notavelmente menos bem vestida que outras pessoas." (Virginia Wolf ${ }^{3}$ )

Gilles Lipovetsky (1989) define como 'a moda dos cem anos' a primeira fase da moda moderna, as evoluções na feição do traje ocorridas no período entre 1850 e 1960. Não que a estética da roupa tenha sido realmente transformada, mas um novo sistema de

\footnotetext{
${ }^{3}$ Diários: Volume III 1925 - 1930. em Fashion Writing 1999
} 
produção e difusão foi instaurado, permanecendo até os dias de hoje uma nova organização do efêmero, que o autor reconhece como uma revolução democrática. Esse período dividiu a expressão de moda em dois horizontes paralelos: a Alta Costura e a confecção industrial, sistema bipolar fundado, por um lado pela criação de luxo e sob medida e, por outro, pela produção em massa, em série e barata. O luxo permaneceu como eufemia na Alta Costura, mas a diferenciação passou a ser definida por signos mais sutis e nuançados, especialmente em griffes, mas também no corte, no tecido e em pequenos detalhes que enobreciam o verdadeiro connosieur; detalhes que asseguravam as funções de distinção e excelência social, promovendo, conforme Lipovetsky, pontos de referência que valorizam sobremaneira os atributos mais pessoais: magreza, juventude, sex appeal etc.

A Alta Costura monopoliza a inovação, lança a tendência do ano; a confecção e as outras indústrias a seguem, inspirando-se nela mais ou menos de perto, com mais ou menos atraso, de qualquer modo, a preços incomparáveis. Se, portanto, a moda moderna se apóia em dois eixos maiores, torna-se como nunca, radicalmente monocéfala. (Lipovetsky 1989: 70)

A moda dos cem anos gera um universo de criação e produção essencialmente feminino, centralizado em Paris, na Alta Costura. Enquanto isso, Londres é o lugar da indústria da confecção. Curiosamente, também centro da então diminuta moda masculina. As duas grandes guerras mundiais certamente marcaram a indústria da moda através dos períodos de crescimento e euforia que as sucederam e que geraram grandes inovações nas criações do traje. Após a primeira guerra, a confecção torna-se mais desenvolvida tecnicamente. Conforme Lipovetsky, ocorrem uma maior divisão do trabalho, o aperfeiçoamento das máquinas e os progressos da indústria química. Após a segunda guerra surgem novos têxteis à base de fibras sintéticas.

Entre todas essas evoluções e revoluções, um evento (cujo início data do século XVIII e cujos ápice e consolidação deram-se ao longo do século XX) tornou-se preponderante na moda do século passado: a feminização da moda e a transformação do universo das roupas em seara feminina. A imagem feminina foi 'desunificada' a partir de então, mostrando os novos papéis sociais desempenhados pela mulher, da aviadora à tenista, da operária à prostituta, da serviçal à boneca de luxo a expressar a riqueza de seu homem.

Até a emergência do sistema da moda, gerado a partir do século XII, homens e mulheres vestiam-se como na antiguidade, como entre os gregos e romanos, com trajes que se assemelhavam a sacos curvilíneos sem costura, sem nenhum ajuste em torno do corpo. Conforme o tecido que caia em torno do corpo passou a ser amarrado, enfaixado, preso com faixas, cintos ou presilhas, partes das formas humanas tornaram-se evidentes através 
Moda, cultura de consumo e modernidade no século XIX

de Valéria Brandini

do traje, todavia, ainda não completamente e não diferenciando formas masculinas e femininas ${ }^{4}$.

Foi com a criação da armadura, gerada para os soldados em guerra, que as partes articuladas e separadas do corpo tornaram-se visíveis. A armadura era construída de forma que as partes do corpo masculino fossem separadas e novamente unidas através de uma veste de metal que compunha a forma do corpo humano.

A partir de então vestes masculinas começaram a ser criadas imitando a armadura, o que gerou a forma de roupa masculina que impera até os dias de hoje e que é melhor representada através do terno de homem. As roupas femininas continuaram a esconder as formas da mulher até o século XX.

Conforme Anne Hollander, no decorrer dos séculos XIV, XV, XVI e início do século XVII, o vestuário masculino se inspirava na armadura para criar formas abstratas rígidas em torno do corpo do homem, levando em conta as articulações, os braços, pernas, tronco, pescoço. Foram criadas calças, culotes, coletes, casacos e por fim a gola de tufos engomados no pescoço.

Enquanto isso, as formas femininas eram escondidas em produções bizarras, como as saias do século XVIII, que transformavam a metade inferior da mulher num painel ou assemelhando uma cortina aberta.

As únicas mudanças extraídas da armadura, para as mulheres, foram o corpete rígido, apertado, uma espécie de cone que parecia servir de pedestal para os seios - e as mangas que saíam dos corpetes.

A parte inferior da veste feminina permaneceu como na antiguidade, como a saia sendo nada mais do que o resquício da antiga roupa em forma de saco, todavia, estilizada ao longo dos séculos, mas sempre escondendo a mulher real e seu corpo articulado, nunca sugerindo a forma do nu.

A idéia de que as saias são femininas e as calças são masculinas é um equívoco histórico. Ambas são resultantes de determinantes culturais do Ocidente, onde a divisão social do trabalho só se tornou igualitária no século XX.

Todavia, a primeira grande conquista feminina que não derivou da forma armadura, é na realidade a minissaia, tão famosa pelas criações de Mary Quant e de Courréges nos anos 1960.

Courréges reivindicou sempre a criação da minissaia para si, a despeito de Mary Quant ser conhecida mundialmente como a inventora da mesma. Quant, enquanto isso, dizia que quem criara a minissaia haviam sido as garotas que desfilavam nas ruas londrinas

\footnotetext{
${ }^{4}$ ver Anne Hollander $O$ sexo e as roupas.
} 
Moda, cultura de consumo e modernidade no século XIX

de Valéria Brandini

nos anos 60, e que ela apenas tinha projetado o estilo para o mundo.

Segundo Anne Hollander, até o século XIX, o universo da alfaiataria masculina e da costura feminina eram separados, homens e mulheres eram seres visuais diferentes. Os alfaiates eram verdadeiros arquitetos do vestuário, e as formas deviam seguir uma lógica calcada no bom gosto e harmonia das formas. Enquanto isso, as costureiras seguiam os delírios estéticos das mulheres, que na época eram conhecidas como vítimas do mau-gosto e da extravagância.

Worth revolucionou esta condição quando dedicou seus talentos à composição indumentária das mulheres. Exímio alfaiate, artesão e conhecedor das artes plásticas, dedicou-se a remodelar a imagem feminina com o rigor da alfaiataria e o "bom senso" de um homem elegante. Sobretudo, Worth consolidou o pensamento de que as mulheres vestidas são representações da fantasia estética masculina.

A ocorrência importante a ser salientada neste tópico, é que a moda dos Cem Anos, a partir de Worth até Cardin, voltada à descoberta do universo feminino, só foi possível porque, com a conversão das mulheres em representantes do status social de seus homens, o universo elegante e sofisticado da alfaiataria voltou-se para a feição da indumentária feminina.

Toda a moda gerada a partir da segunda metade do século XIX, dedicada ao feminino e colocando a indumentária masculina em segundo plano, ilustra um fenômeno social: o interesse dos homens em tornar as mulheres objetos de representação de seus egos. Quando pensamos a expressão de moda emergente no século XIX como um universo feminino, não pensamos em quem controla esse universo

- homens, alfaiates, artesãos, mestres da produção estética a transformar mulheres em objetos de luxo.

Worth e alfaiates que, seguindo seus passos, dedicaram-se à construção de bonecas de luxo, eram mestres da elegância que acompanhavam as manifestações artísticas da época e que primavam por tornar as damas em evidência num híbrido fantasioso dividido entre musa inspiradora das artes plásticas e objeto elegante e virtuoso da cobiça de outros homens.

A moda de então, feminina e ostentatória, era uma construção masculina baseada em fantasias eróticas impulsionadas pela literatura e as artes plásticas do século XIX, a representar a realidade por trás da moda dos cem anos: a construção da imagem feminina segundo o repertório de fantasias estéticas e desejos de poder masculinos.

Enquanto a expressão de moda agradava aos homens por elucidar os desejos masculinos e tornar suas mulheres espelhos de suas riquezas, ela seduzia as mulheres ao 
torná-las objetos do desejo masculino. Como em muitas artes plásticas, a beleza deixou de ser o essencial na moda e cedeu lugar a delírios estéticos dos mestres alfaiates. É necessário salientar que muito da criação em moda no século XIX foi influenciado pela representação artística de pintores da época, que, não só criavam divas a serem copiadas pelos criadores de moda, como também mostravam às mulheres o que as tornava fascinantes dentro de suas roupas - as posturas e gestos retratados na arte que serviram para criar um verdadeiro teatro social da moda a partir de então. (Hollander 1996)

A dissociação entre moda e beleza é impulsionada pelas formas geradas pelas fantasias inconscientes que iniciam na psique individual e remontam o inconsciente coletivo. Por isso a moda do fim do século XIX foi considerada ridícula e cada vez mais contraria a estética formal, tomando corpo com o desejo subversivo das sociedades contemporâneas.

Segundo Anne Hollander, a moda representa o que prevalece no imaginário coletivo num dado momento sócio-histórico; ela ilustra a vida coletiva como se fosse uma narrativa pessoal, com sua trajetória linear e subjetiva através do tempo. A moda é uma forma coletiva, que se utiliza das formas que jazem nas profundezas psíquicas individuais e que se torna guiada pela imagética disponível nas artes disponíveis. A moda é, pois, um teatro silencioso.

Os desfiles de moda organizados, como conhecemos hoje, tiveram início em Paris nos anos 1908 e 1910, tornando-se verdadeiros espetáculos nos salões das grandes casas, mas não ocorriam com datas fixas, mas ao longo do ano, arbitrariamente. Esses eventos ocorriam, sobretudo, para que compradores estrangeiros pudessem escolher os modelos a serem comprados para reprodução em grande série em seus países. Conforme Lipovetsky:

Munidos dos modelos e das fichas de referência dando as indicações necessárias para a
reprodução do vestido, os fabricantes, à exceção contudo dos fabricantes franceses que não
tinham acesso imediatamente às novidades de estação por razões evidentes de
exclusividade, podiam reproduzir as criações parisienses simplificando-as: assim, muito
rapidamente, em algumas semanas, a clientela estrangeira podia vestir-se na última moda
da Alta Costura a preços acessíveis, ou até muito baixos, segundo a categoria da
confecção. De maneira que a Alta Costura menos acelerou a moda, como se crê por vezes,
do que a regularizou.

A partir dos anos 1920, após a I Guerra Mundial, o universo do vestuário feminino sofreu uma revolução através dos novos criadores de moda, principalmente os couturiers franceses. A moda, que até então convertia a imagem feminina em fantasia ou adequação ao desejo masculino, passou a centrar seu interesse na forma como as mulheres sentiam seu corpo, sua condição e como viviam suas vidas. Pela primeira vez, em séculos de moda, a roupa feminina deixou de se inspirar na gramática do vestuário masculino para criar uma 
Moda, cultura de consumo e modernidade no século XIX

de Valéria Brandini

moda não só feminina, mas que ia ao encontro dos anseios das mulheres.

As atenções voltaram-se para como a mulher sentia e queria se sentir em seu corpo e não para como os homens preferiam vê-las ou senti-las. Pela primeira vez considerou-se a nudez feminina e a forma a ser trabalhada com soluções arquitetônicas. Quando a moda passou a sugerir o nu feminino e a forma real passou a ser considerada, sem enchimentos ou apertos, curiosamente, surgiu o estilo 'garçon' ou rapaz, que fazia uma alusão às pequenas e estreitas proporções femininas como as de um 'moleque'.

As mulheres deixaram de parecer uma árvore, (HOLLANDER, 1996) um quadro ou uma casa, um objeto inanimado e acolhedor para sugerir a nudez real e a vida moderna na metrópole. Pela primeira vez o corpo feminino foi vestido para o trabalho urbano, para um lazer mais espontâneo e menos ritualístico, como nos eventos sociais da aristocracia e da burguesia emergente do século XIX.

A modernidade do século XIX gerara definitiva e irrevogavelmente a era da moda associada ao desenvolvimento tecnológico, ao acúmulo de capital e à aceleração do tempo vivido em metrópole. Essa moda só foi possível porque emergiu paralelamente ao mundo moderno e ao decréscimo da ritualização do processo artístico, também da deificação da criação em arte e da associação entre produção industrial e produção artística, ao exemplo da solidariedade entre produtores de diversos segmentos ressaltada por Walter Benjamin, em O Autor como Produtor, (1936), onde a sacralização da obra artística e sua 'aura' sucumbem irremedialvelmente.

Um paralelo entre a formação dos couturiers, (mestres alfaiates com aptidões artísticas que criavam e produziam roupas para mulheres a partir do século XX) e a consolidação da Obra de Arte na Era de sua Reprodutibilidade Técnica (Benjamin) pode ser traçado para a elucidação dos caminhos da expressão de moda a partir da modernidade. Roupas feitas em série - com o glamour e a arte dos mestres alfaiates, que, ao mesmo tempo em que se vangloriavam do usufruto das tecnologias de ponta para a feição do traje, paradoxalmente glorificavam o universo da couture como um apêndice das belas artes que se utilizava do gênio criador dos couturiers para uma produção elaborada - constituem um fenômeno que notavelmente vem a representar a condição imposta pela modernidade e os caminhos abertos a serem trilhados posteriormente pela pós-modernidade.

A moda acompanhou, entre tantos eventos, a elevação do status estético do design industrial. A mulher passou de objeto de desejo a objeto de design e, a partir de então, ela passou a se alimentar de toda a sorte de evoluções arquitetônicas e do design em geral para a criação da moda no século XX.

As saias foram encurtando com o passar das décadas e as pernas femininas foram 
tornando-se uma visão costumeira do cotidiano. As calças para mulheres surgiram por volta de 1911 na Europa, como uma possibilidade audaciosa da Alta Costura. A androginia tornou-se elegante entre as classes mais elevadas e seu apelo erótico evidenciou-se mais ainda nas décadas posteriores, culminando com a indumentária masculina acompanhada de cartola, usada pela diva Marlene Dietrich na década de 1930.

Como o par constante da moda não é a beleza, mas a sedução, a moda feminina não acrescentou os uniformes à roupa das mulheres por uma questão de pura necessidade prática, pois as mulheres dos séculos anteriores já cavalgavam e jogavam tênis com roupas volumosas e desconfortáveis, mas porque a inversão sexual no traje era uma conquista erótica da moda do século passado.

\section{CONCLUSÃO}

$\mathrm{Na}$ imagem e no corpo "fabricados" pela moda no século XIX, podemos "ler" o avanço da ciência, tecnologia, globalização, início do consumerismo, relações de gênero, política, economia. Enfim, tudo o que se refere ao progresso, evolução, ruptura, ethos, está escrito na fabricação pela moda, no que ele representa, em como ele é produzido, para quem é produzido e qual o seu objetivo.

A moda, enquanto forma, constituição da imagem numa referência ao "formismo" de que nos fala Maffesoli (1996:127) no livro No fundo das aparências, nos mostra que a imagem (ou aparência) é formadora e que a aparência é, ao mesmo tempo, parte integrante de um exemplo dado e meio de compreender este conjunto, o todo social. A aparência nos mostra o que é aleatório e ao mesmo tempo dá coerência à totalidade.

A pele é o que há de mais frágil, vulnerável à exterioridade que cerca o ser humano e, ainda assim, ela exprime a força do homem na dominação do meio, como ressalta Maffesoli, sempre próxima a rasgar-se em tumultos e conflitos, ela se estica na derrisão do vestuário (punk) e nos paroxismos da postura (como o skinhead), em suma exacerba-se em todos os excessos, é o trágico à flor da pele que se exprime, é a fatalidade que é aceita. É a relação do homem com o meio, em sua forma simbólica que pode ser lida na aparência da pele e no que usamos sobre ela.

É o que pode incitar o observador social, ou pura e simplesmente, o homem de sociedade, a não considerar a teatralidade cotidiana uma simples frivolidade sem importância, mas um vetor de conhecimento, uma alavanca metodológica de importância para a compreensão da estrutura orgânica. Será necessário empenhar-se em descrever os estilos, a reconhecer os ritos, a captar os modos de fazer e os de dizer que caracterizavam as relações sociais. A Escola de Chicago, na linha de George Simmel, falava da necessidade de saber "aflorar à superficie das coisas" para captar uma estilística social. É necessário precisar que essa abordagem afável inscreve-se no jogo de interações que se estabelece entre a imagem do eu 
$e$ as imagens do ambiente natural e social. Imagens (do eu e do ambiente) que não deixam de representar seus papéis nessas situações de diversas ordens, que constituem as sociedades. As maneiras do ser não dependendo apenas de causas exteriores e dominantes, mas também de sua dinâmica interna, de uma espécie de força imanente que, qualquer que seja o nome que se lhe dê, traduz o vitalismo e o perdurar dos conjuntos sociais. Parece-me que essa força encontra sua origem na reunião do mundo das imagens. (Maffesoli 1996:129)

Em relação ao todo social, o corpo é a unidade frágil, perdendo-se em meio à multidão, como ressalta Sennet (1982). A pele está para o corpo humano (em relação ao pensamento de Maffesoli) como o corpo humano está para a sociedade. O corpo expressa o funcionamento da máquina social, na teatralidade cotidiana que representa (ou mesmo dramatiza) a estrutura orgânica do todo social. O corpo como unidade mínima reflete a estrutura deste todo. Com a moda, o corpo vestido de significações sociais marca o sinal dos tempos, reflete a sociedade e seus valores e desejos.

Este corpo se veste da sociedade (a cosmologia) e a relação entre a moda e a moderna urbe ocidental forma uma aliança representativa das estruturas de significação inerentes ao ethos social. A própria frivolidade da moda é um aspecto de profundidade por representar um valor social - a superficialidade como performance do ator social.

Assim, com a moda, indivíduos e grupos "vestem a cultura" que estrutura sua sociedade, confeccionada com os signos materiais produzidos pelo meio, pela vivência humana e construção da história, vista pela associação, incorporação, aproximação entre a imagem de uma sociedade, as pessoas, os indivíduos e os grupos sociais com as suas vivências, materiais e psicológicas e funcionais em seu tempo e espaço próprio.

Significados "gravados na roupa" e a construção estética dos mesmos através do traje com expressão de moda são elementos de uma cosmologia urbana contemporânea, em que a história social se escreve e se inscreve nos signos do vestuário. Para além de roupa e para além de objeto signo, dado que essa moda é por vezes 'esculpida', marcada, gravada sobre o corpo. Como uma moda/totem, ela incorpora a cultura e nos veste dela.

\section{REFERÊNCIAS BIBLIOGRÁFICAS}

BAUDRILLARD, Jean. O Sistema dos Objetos. São Paulo, Perspectiva. 1997.

BARNARD, Michael. Fashion as Communication. London, Routledge, 2001.

BOURDIEU, Pierre. "Le couturier et as griffe": contribution à une théorie de la magie. Actes de la recherche en sciences sociales. Paris, 1975.

BREWARD, Christopher. The Culture of Fashion. Manchester, Manchester University Press, 1995. 
Moda, cultura de consumo e modernidade no século XIX

de Valéria Brandini

CANEVACCI, Massimo. Cultura eXtrema, Mutazione Giovanili tra i corpi delle metropoli.

Roma. Meltemi editore. 1999

FREYRE, Gilberto. Modos de Homem e Modas de Mulher. Rio de Janeiro, Editora Record, 1996.

GIDDENS, Antony. As Consequencias da Modernidade. São Paulo, Editora da UNESP, 1992

HOLLANDER, Anne. O Sexo e as Roupas, A evolução do traje moderno. Rio de Janeiro, Rocco. 1996

KOHLER, Carl. A História do Vestuário. São Paulo, Martins Fontes, 2001.

LIPOVETSKY, Gilles. O império do efêmero, São Paulo, Companhia das Letras, 1989.

LOPES, Maria Immacolata V. de. Pesquisa em Comunicação -Formulação de um modelo metodológico. São Paulo, Edições Loyola, 1990.

LURIE, Alison. A Linguagem das Roupas. Rio de Janeiro, ed Rocco, 1997

Comunicação para o mercado. (org.) Tupã Gomes Corrêa, São Paulo, Edicom. 1995.

MATTELART, Armand. Comunicação Mundo, História da Idéias e das Estratégias. Petrópolis, Vozes, 1991.

OLALQUIAGA, Celeste. Megalópolis, Contemporary Cultural Sensibilities. Universisty of Minnesota Press, Mineápolis, London, 1992.

PERNIOLA, Mario. Il sex appeal dellínorganico. Totino, Einaudi, 1994.

RIESMAN, David. A Multidão Solitária. São Paulo, Ed. Perspectiva, 1985.

SENNET, Richard. O Declínio do Homem Público. As Tiranias da Intimidade. São Paulo. Companhia das Letras, 1982.

SIMMEL, George. "A metrópole e a Vida Mental" (1902) in VELHO, Gilberto. O Fenômeno Urbano. Rio de Janeiro, Zahar. 1967.

VILLAÇA, Nízia e GÓES, Fred. Em Nome do Corpo. Rio de Janeiro, Rocco. 1998.

VINCENT-RICARD, Françoise. As Espirais da Moda. Rio de Janeiro, Paz e Terra. 1989.

WILSON, Elizabeth. Enfeitada de Sonhos, Moda \& Modernidade. Lisboa, Edições 70, 1986.

Agradecimentos: à Fundação de Amparo à Pesquisa do Estado de São Paulo, instituição financiadora desta pesquisa.

Artigo recebido em 26/3/2009.

Aprovado em 30/4/2009. 